\title{
High plasma concentrations of asymmetric dimethylarginine inhibit ischemic cardioprotection in hypercholesterolemic rats
}

\author{
M.B.P. Landim, P.M.M. Dourado, A. Casella-Filho, A.C.P. Chagas and P.L. da-Luz
}

Unidade de Aterosclerose, Instituto do Coração, Faculdade de Medicina, Universidade de São Paulo, São Paulo, SP, Brasil

\begin{abstract}
A low concentration of nitric oxide associated with a high concentration of asymmetric dimethylarginine (ADMA) can explain the lack of ischemic cardioprotection observed in the presence of hypercholesterolemia. The objective of the present study was to evaluate the effect of hypercholesterolemia on ischemic pre- and postconditioning and its correlation with plasma concentrations of ADMA. Male Wistar rats (6-8 weeks old) fed a $2 \%$ cholesterol diet $(n=21)$ for 8 weeks were compared to controls $(n=25)$ and were subjected to experimental myocardial infarction and reperfusion, with ischemic pre- and postconditioning. Total cholesterol and ADMA were measured in plasma before the experimental infarct and the infarct area was quantified. Weight, total cholesterol and plasma ADMA (means \pm SE; $1.20 \pm 0.06,1.27 \pm 0.08$ and $1.20 \pm 0.08$ vs 0.97 $\pm 0.04,0.93 \pm 0.05$ and $0.97 \pm 0.04 \mu \mathrm{M}$ ) were higher in animals on the hypercholesterolemic diet than in controls, respectively. Cardioprotection did not reduce infarct size in the hypercholesterolemic animals (pre: $13.55 \%$ and post: $8 \%$ compared to $7.95 \%$ observed in the group subjected only to ischemia and reperfusion), whereas infarct size was reduced in the animals on a normocholesterolemic diet (pre: $8.25 \%$ and post: $6.10 \%$ compared to $12.31 \%$ ). Hypercholesterolemia elevated ADMA and eliminated the cardioprotective effects of ischemic pre- and postconditioning in rats.
\end{abstract}

Key words: Hypercholesterolemia; Cardiotonics; Nitric oxide; Risk factors; Asymmetric dimethylarginine

\section{Introduction}

The literature is not unanimous about the influence of hypercholesterolemia on the infarct size after ischemic pre- and postconditioning. In hyperlipidemic patients subjected to coronary angioplasty, the loss of the beneficial effect caused by classical ischemic preconditioning is correlated with increased levels of total cholesterol (TC) and cholesterol associated with low-density lipoprotein (LDL) cholesterol (1). Additionally, the limiting effect of infarct size caused by this form of cardioprotective ischemia is attenuated in rabbits fed a diet enriched with up to $1 \%$ cholesterol (2). However, there are reports based on research with animals that did not demonstrate an influence of hyperlipidemia on the beneficial effects of classical ischemic preconditioning (3-6).

The effects of hyperlipidemia on myocardial postconditioning have been studied less, possibly due to the fact that this form of protection has only been studied recently. Some studies have shown the lack of beneficial effects of postconditioning in animals with experimental hyperlipidemia (3). In contrast, Donato et al. (7) showed a reduction of myocardial damage in a model of experimental myocardial infarction and hypercholesterolemia involving rabbits subjected to ischemic postconditioning.

\section{The role of nitric oxide (NO) and asymmetric dimethylarginine (ADMA)}

A reduction in the bioavailability of $\mathrm{NO}$ due to increased nitrosactive stress, among other mechanisms, can contribute to the loss of the effect of myocardial preconditioning in some hyperlipidemic animals (2). In classical preconditioning, endogenous NO does not appear to play an important role, whereas exogenous NO causes myocardial protection (8). In late preconditioning, which occurs 24 to $96 \mathrm{~h}$ after sublethal ischemia, experimental studies have indicated that hypercholesterolemia suppressed the protection of the myocardium

Correspondence: M.B.P. Landim, Unidade de Aterosclerose, INCOR, FM, USP, Av. Dr. Enéas C. Aguiar, 44, 05403-900 São Paulo, SP, Brasil. Fax: +55-86-3221-3400. E-mail: landim@cardiol.br

Received August 6, 2012. Accepted January 29, 2013. First published online. 
induced by NO (9). NO generated by endothelial NO synthase (eNOS) triggers a cascade of molecular events that culminate in the late activation of inducible NOS that provides cardioprotection (10).

A study that applied postconditioning showed a lack of protection when NOS was inhibited by L-NAME (11). This result shows that $\mathrm{NO}$, probably generated by eNOS, is necessary for the limitation of myocardial necrosis, with its relevant clinical effects, provoked by postconditioning.

The inhibition of NOS and consequent endothelial dysfunction is obtained in animals with induced atherosclerosis $(12,13)$. In humans, evidence shows a positive correlation between the blood concentrations of ADMA and cholesterol (14). However, some studies did not find this correlation (15).

Vegh et al. (16) reported that the beneficial effect of ischemic preconditioning to avoid arrhythmias induced by ischemia and reperfusion during the first window of myocardial protection was eliminated by L-NAME. Penna et al. (17) demonstrated that L-NAME infusion for 3 min completely evaded the protection induced by postconditioning. The systemic administration of NOS inhibitors during ischemia and just before reperfusion caused an increase in infarct size, an effect that could be reversed by the administration of L-arginine (18).

The objective of the present study was to evaluate the effect of hypercholesterolemia on the infarct area in rats subjected to ischemia and reperfusion, alone or associated with ischemic pre- and postconditioning, and high plasma concentrations of ADMA.

\section{Material and Methods}

Male Wistar rats (Rattus norvegicus) aged 6 to 8 weeks were used. The animals were kept at room temperature, varying from $22^{\circ}$ to $24^{\circ} \mathrm{C}$, on a 12-h lightdark cycle.

Control animals $(n=25)$ were fed a normocholesterolemic diet (Nuvilab Nutrientes S/A, Brazil) while experimental animals $(n=21)$ were fed exclusively a diet enriched with $2 \%$ cholesterol, provided by Nutri Experimental ${ }^{\circledR}$, Brazil, for a period of 8 weeks (Table 1). In previous studies (19), similar diets also increased the levels of cholesterol.

All animals were subjected to an experimental myocardial infarct (20) by means of occlusion of the anterior descending coronary artery (ADA), for a period of $30 \mathrm{~min}$, followed by reperfusion (open artery).

Three groups of animals were used as controls. The ischemia/reperfusion group ( $/ / R)$ was subjected just to ADA occlusion for $30 \mathrm{~min}$ (lethal ischemia), followed by reperfusion. The I/R with preconditioning group (PC) (21) was subjected to three periods of $3 \mathrm{~min}$ of ischemia, interspersed with an equal period of reperfusion, before lethal ischemia. The $\mathrm{I} / \mathrm{R}$ with postconditioning group (POC) (22) was subjected to 3 periods of $10 \mathrm{~s}$ of ischemia
Table 1. Composition of the hyperlipidic diet used in the intervention group.

\begin{tabular}{lc}
\hline Component & Quantity (\%) \\
\hline Carbohydrates* $^{*}$ & 51.95 \\
Protein source $^{\#}$ & 20.00 \\
Lipids $^{+}$ & 18.00 \\
Fibers & 5.00 \\
Mineral mix & 1.00 \\
Vitamin mix & 3.00 \\
L-cysteine & 0.30 \\
Choline bitartrate & 0.25 \\
Cholic acid & 0.50 \\
Total & 100.00 \\
\hline
\end{tabular}

${ }^{*}$ Carbohydrate fractions: $55.8 \%$ starch, $25.8 \%$ malt dextrin, and $18.3 \%$ sucrose. \#Protein source = commercial casein $(85 \%$ protein). ${ }^{+}$Lipid fraction $=66.7 \%$ coconut oil, $26.4 \%$ soybean oil, and $6.9 \%$ cholesterol. The vitamin and mineral mixtures followed the recommendations of the American Institute of Nutrition (AIN-93G).

interspersed with equal periods of reperfusion in the first minute after lethal ischemia. The other 3 groups that received a cholesterol-rich diet were subjected to the same protocols (I/R-HYPER, PC-HYPER and POCHYPER).

Blood samples were collected before the experimental infarct by cannulating the right jugular vein and the blood concentrations of TC were analyzed using the trinderenzymatic method (Labtest ${ }^{\mathbb{R}}$ Diagnóstico S/A, Brazil) and ADMA by ELISA (LDL-Diagnostika ${ }^{\circledR}$, Germany).

The anesthetics xylazine $(10 \mathrm{mg} / \mathrm{kg})$ and ketamine (90 $\mathrm{mg} / \mathrm{kg}$ ) administered intraperitoneally, and $19.1 \%$ potassium chloride and $4 \%$ formaldehyde were used in this study, as described below.

After anesthesia, the animals were intubated with a 14-gauge polyethylene cannula and connected to a Harvard $^{\mathbb{R}}$ mechanical ventilator, model 683 (Harvard Apparatus Inc., USA), with a current volume set at $1.1 \mathrm{~mL} / 100 \mathrm{~g}$ body weight, and a respiratory frequency of $70-75 / \mathrm{min}$. A polyethylene catheter (PE 50) was used to collect blood samples.

The fourth or fifth intercostal space was opened and the heart exposed. The ADA was occluded with a 6.0 polypropylene thread (Prolene ${ }^{\mathbb{R}}$, Ethicon Inc., USA) at its proximal third, about $1 \mathrm{~mm}$ from the origin, pressing against a polyethylene catheter. After liberation, the thread was removed from the surgical field.

After the end of the procedure, the chest wall was closed (thread 4.0 Mononylon ${ }^{\circledR}$, Ethicon Inc., Brazil) and the animals were placed in boxes heated with infrared lights and provided with supplemental oxygen for 1 to $2 \mathrm{~h}$.

Eight days after acute myocardial infarction, with the animals anesthetized, an incision was made extending from the abdomen to the chest. The heart was exposed and a saline solution containing $14 \mathrm{mM} \mathrm{KCl}$ was 
Table 2. Weight of the animals prior to experimental infarction.

\begin{tabular}{lcccc}
\hline Group & Mean \pm SE $(\mathrm{g})$ & SD & Minimum & Maximum \\
\hline I/R $(\mathrm{n}=10)$ & $247.80 \pm 13.81$ & 43.64 & 171 & 307 \\
PC $(\mathrm{n}=7)$ & $304.00 \pm 10.93$ & 28.86 & 273 & 347 \\
POC $(\mathrm{n}=8)$ & $256.00 \pm 22.70$ & 64.03 & 170 & 366 \\
I/R-HYPER $(\mathrm{n}=8)^{*}$ & $409.00 \pm 12.41$ & 35.02 & 345 & 473 \\
PC-HYPER $(\mathrm{n}=5)^{*}$ & $451.20 \pm 23.70$ & 52.87 & 406 & 528 \\
POC-HYPER $(\mathrm{n}=8)^{*}$ & $391.38 \pm 12.80$ & 36.12 & 314 & 426 \\
\hline
\end{tabular}

$\mathrm{I} / \mathrm{R}=$ isolated ischemia/reperfusion; $\mathrm{PC}=\mathrm{I} / \mathrm{R}$ with preconditioning; $\mathrm{POC}=\mathrm{I} / \mathrm{R}$ with postconditioning; $\mathrm{I} / \mathrm{R}-\mathrm{HYPER}=\mathrm{I} / \mathrm{R}$ and hypercholesterolemia; PC-HYPER $=\mathrm{I} / \mathrm{R}$ with preconditioning and hypercholesterolemia; POC-HYPER $=\mathrm{I} / \mathrm{R}$ with postconditioning and hypercholesterolemia; $n=$ number of animals. ${ }^{*} P<0.05$ compared to the normocholesterolemic diet group (ANOVA).

administered under constant pressure of $80 \mathrm{mmHg}$, followed by $4 \%$ formaldehyde. The heart was excised and kept in formalin for $24 \mathrm{~h}$. The hearts were then sectioned along the midpoint between basis and apex and a slice was embedded in paraplast for histological sections. Sections of $3 \mu \mathrm{M}$ were stained with hematoxylin-eosin for qualitative assessment and with Masson's trichrome (blue stain) in the scar area, which was then measured by computerized planimetry (Leica Imaging Systems ${ }^{\mathbb{R}}$, UK); the images were analyzed with a specific software (ImageQuant ${ }^{\circledR}$, Leica ${ }^{\mathbb{R}}$ ).

The variables were measured at a single time and are reported as means \pm SE, SD and the minimum and maximum values. Group means were evaluated by ANOVA with classification factor. When significant results were obtained, the Tukey test was used to determine differences. The SPSS ${ }^{\mathbb{R}}$ software (SPSS Inc., USA) was applied and the level of significance was set at $P<0.05$.

\section{Results}

Significant differences in the weight (Table 2) and plasma concentrations of cholesterol (Table 3) of the animals on the hyperlipidemic diet were observed compared with those on the normocholesterolemic diet.

Hypercholesterolemia contributed to increase the concentrations of ADMA (Table 4). A statistically significant difference was observed between the hypercholesterolemic and normocholesterolemic groups, whereas no difference was observed between animals in the groups subjected to the same diet.

In the groups without hypercholesterolemia, pre- and postconditioning protected the myocardium with smaller infarcts; a fact not observed in the hypercholesterolemic animals (Table 5).

\section{Discussion}

A hyperlipidemic diet given to rats over a period of 8 weeks caused weight gain and increased concentrations of TC (Tables 2 and 3). However, the cholesterol concentrations detected were not as high as the levels observed by Matos et al. (19) even though the average weight gain was significant (Table 2).

The size of the infarct area considered was a percentage of the total transverse area of the left ventricle and not a percentage of the risk area. Triphenyltetrazolium was used to quantify the viable myocardium, as described by Dow and Kloner (23). Our infarction model with reperfusion and survival may also have contributed in some way to a lesser extent of myocardial necrosis, although reperfusion per se contributes to myocyte death (24).

Hypercholesterolemia did not influence the size of the infarcted area in the groups submitted to ischemia and reperfusion without myocardial protection. A smaller area of necrosis was observed, but without statistical significance (Table 5). This result is comparable to that obtained by Girod et al. (25) who studied rats fed a

Table 3. Total cholesterol of the animals prior to experimental infarction.

\begin{tabular}{lcrrr}
\hline Group & Mean \pm SE $(\mathrm{mg} \%)$ & SD & Minimum & Maximum \\
\hline I/R $(\mathrm{n}=10)$ & $69.50 \pm 4.70$ & 14.86 & 49 & 85 \\
PC $(\mathrm{n}=7)$ & $73.71 \pm 4.17$ & 11.03 & 61 & 91 \\
POC $(\mathrm{n}=8)$ & $75.25 \pm 4.18$ & 11.80 & 53 & 88 \\
l/R-HYPER $(\mathrm{n}=8)^{*}$ & $133.38 \pm 8.65$ & 24.40 & 109 & 181 \\
PC-HYPER $(\mathrm{n}=5)^{*}$ & $112.00 \pm 5.88$ & 13.13 & 94 & 123 \\
POC-HYPER $(\mathrm{n}=8)^{*}$ & $129.00 \pm 10.72$ & 30.24 & 104 & 198 \\
\hline
\end{tabular}

For abbreviations, see legend to Table 2. ${ }^{*} \mathrm{P}<0.05$ compared to the normocholesterolemic diet group (ANOVA). 
Table 4. Plasma ADMA of the animals prior to experimental infarction.

\begin{tabular}{|c|c|c|c|c|}
\hline Group & Mean \pm SE $(\mu \mathrm{M})$ & SD & Minimum & Maximum \\
\hline $\mathrm{I} / \mathrm{R}(\mathrm{n}=10)$ & $0.97 \pm 0.04$ & 0.13 & 0.81 & 1.18 \\
\hline$P C(n=7)$ & $0.93 \pm 0.05$ & 0.14 & 0.77 & 0.19 \\
\hline $\mathrm{POC}(\mathrm{n}=8)$ & $0.97 \pm 0.04$ & 0.14 & 0.76 & 1.18 \\
\hline I/R-HYPER $(n=8)^{*}$ & $1.20 \pm 0.06$ & 0.19 & 0.83 & 1.45 \\
\hline PC-HYPER $(n=5)^{*}$ & $1.27 \pm 0.08$ & 0.19 & 0.99 & 1.51 \\
\hline POC-HYPER $(n=8)^{*}$ & $1.20 \pm 0.08$ & 0.25 & 0.89 & 1.67 \\
\hline
\end{tabular}

For abbreviations, see legend to Table 2. ${ }^{*} \mathrm{P}<0.05$ compared to the normocholesterolemic diet group (ANOVA).

cholesterol- enriched diet. Paradoxically, some investigators have shown a protective effect of hypercholesterolemia against myocardial damage secondary to ischemia and reperfusion $(26,27)$.

When the cardioprotective effects were evaluated in the groups receiving a normocholesterolemic diet (Table 5), there was a smaller area of necrosis in the group subjected to both procedures (pre- and postconditioning). This result is comparable to those reported in the literature, which showed the benefits of these procedures for many species, including humans and rodents (23).

Beneficial cardioprotective effects were not observed in the hypercholesterolemic animals. The extension of myocardial damage was greater in the groups subjected to preconditioning (PC-HYPER) than in the groups without cardioprotection (I/R-HYPER), although without statistical significance (Table 5). The lack of ischemic cardioprotection is also observed in humans and correlates with the increased levels of TC and LDL cholesterol (1).

In contrast to our results, some literature reports have demonstrated that hyperlipidemia did not eliminate the favorable effects of classical myocardial preconditioning in the animals (3-6). The literature also shows that myocardial postconditioning acts beneficially even in hypercholesterolemic animals (7). However, some investigators have obtained results similar to ours, in that the tissue damage was not lower in hypercholesterolemic animals subjected to this form of modified reperfusion, which is cardioprotective (3).

The reduced bioavailability of $\mathrm{NO}$ can explain the lack of cardioprotection in the animals receiving a hyperlipidemic diet (2), as extensively reported regarding late myocardial preconditioning (10). However, the importance of NO in the classic form remains a subject for discussion (12). Regarding myocardial postconditioning, we also found evidence of a role of $\mathrm{NO}$ in the intrinsic cardioprotective mechanism (28).

The increased concentration of ADMA in the presence of hypercholesterolemia can be responsible for the low bioavailability of NO. The plasma concentrations of ADMA did not differ significantly between the normocholesterolemic groups, whose values, as expected, were within normal limits for the method used (29) (Table 4).

ADMA concentrations were significantly increased in the animals receiving the hypercholesterolemic diet compared to the animals receiving the normocholesterolemic diet, showing that the increased cholesterol levels contributed to the elevation of ADMA.

In our opinion, the elevation of ADMA and, indirectly, the blocking of eNOS represent a very reasonable hypothesis to explain the lack of beneficial effects of both pre- and postconditioning.

More studies are necessary, perhaps using a more appropriate animal model of endothelial dysfunction associated with pathological levels of this NOS inhibitor. An alternative would be to show a direct action of ADMA by injecting it into the animal at the time of ischemia and reperfusion, with and without cardioprotective measures.

Because the oxidized LDL is involved in ADMA elevation and is associated with reduced NO production and impaired endothelium-dependent vasodilation (30),

Table 5. Infarct size 8 days after experimental ischemia.

\begin{tabular}{|c|c|c|c|c|}
\hline Group & Mean \pm SE $(\%)$ & SD & Minimum & Maximum \\
\hline I/R $(n=10)$ & $12.31 \pm 1.37$ & 4.34 & 4.77 & 16.94 \\
\hline$P C(n=7)^{*}$ & $8.25 \pm 1.87$ & 4.95 & 2.40 & 18.15 \\
\hline $\mathrm{POC}(\mathrm{n}=8)^{*}$ & $6.10 \pm 0.95$ & 2.70 & 2.36 & 10.43 \\
\hline I/R-HYPER (n = 8) & $7.95 \pm 0.84$ & 2.38 & 4.35 & 10.76 \\
\hline PC-HYPER $(n=5)$ & $13.55 \pm 1.16$ & 2.60 & 10.54 & 16.64 \\
\hline POC-HYPER $(\mathrm{n}=8)$ & $8.00 \pm 1.62$ & 4.57 & 2.94 & 15.18 \\
\hline
\end{tabular}

For abbreviations, see legend to Table 2. ${ }^{*} \mathrm{P}<0.05$ compared to the $\mathrm{I} / \mathrm{R}$ group (ANOVA). 
another alternative experimental model could be to inject the animals with lipoprotein modified with oxidants in order to cause an elevation of ADMA and the consequent NOS inhibition and endothelial dysfunction.

In conclusion, a hypercholesterolemic diet eliminated the cardioprotective effects of ischemic myocardial pre- and postconditioning in rats. In addition, according

\section{References}

1. Kyriakides ZS, Psychari S, lliodromitis EK, Kolettis TM, Sbarouni E, Kremastinos DT. Hyperlipidemia prevents the expected reduction of myocardial ischemia on repeated balloon inflations during angioplasty. Chest 2002; 121: 1211-1215, doi: 10.1378/chest.121.4.1211.

2. Ferdinandy $P$, Schulz R. Nitric oxide, superoxide, and peroxynitrite in myocardial ischaemia-reperfusion injury and preconditioning. $\mathrm{Br} J$ Pharmacol 2003; 138: 532-543, doi: 10.1038/sj.bjp.0705080.

3. Iliodromitis EK, Zoga A, Vrettou A, Andreadou I, Paraskevaidis IA, Kaklamanis $L$, et al. The effectiveness of postconditioning and preconditioning on infarct size in hypercholesterolemic and normal anesthetized rabbits. Atherosclerosis 2006; 188: 356-362, doi: 10.1016/j.atherosclerosis.2005.11.023.

4. Jung O, Jung W, Malinski T, Wiemer G, Schoelkens BA, Linz W. Ischemic preconditioning and infarct mass: the effect of hypercholesterolemia and endothelial dysfunction. Clin Exp Hypertens 2000; 22: 165-179, doi: 10.1081/CEH100100070.

5. Kremastinos DT, Bofilis E, Karavolias GK, Papalois A, Kaklamanis L, lliodromitis EK. Preconditioning limits myocardial infarct size in hypercholesterolemic rabbits. Atherosclerosis 2000; 150: 81-89, doi: 10.1016/S00219150(99)00389-5.

6. Li G, Tokuno S, Tahep IP, Vaage J, Lowbeer C, Valen G. Preconditioning protects the severely atherosclerotic mouse heart. Ann Thorac Surg 2001; 71: 1296-1303, doi: 10.1016/ S0003-4975(00)02608-4.

7. Donato M, D'Annunzio V, Berg G, Gonzalez G, Schreier L, Morales $C$, et al. Ischemic postconditioning reduces infarct size by activation of $A 1$ receptors and $K+($ ATP) channels in both normal and hypercholesterolemic rabbits. $J$ Cardiovasc Pharmacol 2007; 49: 287-292, doi: 10.1097/ FJC.0b013e31803c55fe.

8. Nakano A, Liu GS, Heusch G, Downey JM, Cohen MV. Exogenous nitric oxide can trigger a preconditioned state through a free radical mechanism, but endogenous nitric oxide is not a trigger of classical ischemic preconditioning. $J$ Mol Cell Cardiol 2000; 32: 1159-1167, doi: 10.1006/ jmcc.2000.1152.

9. Tang XL, Stein AB, Shirk G, Bolli R. Hypercholesterolemia blunts NO donor-induced late preconditioning against myocardial infarction in conscious rabbits. Basic Res Cardiol 2004; 99: 395-403, doi: 10.1007/s00395-004-0485-4.

10. Bolli R, Dawn B, Tang XL, Qiu Y, Ping P, Xuan YT, et al. The nitric oxide hypothesis of late preconditioning. Basic Res Cardiol 1998; 93: 325-338, doi: 10.1007/s003950050101.

11. Yang XM, Philipp S, Downey JM, Cohen MV. Postconditioning's protection is not dependent on circulating to our results, ADMA increased significantly and probably was involved in the lack of protection by both cardioprotective phenomena observed in this study.

\section{Acknowledgments}

\author{
Research supported by FAPESP.
}

blood factors or cells but involves adenosine receptors and requires PI3-kinase and guanylyl cyclase activation. Basic Res Cardiol 2005; 100: 57-63, doi: 10.1007/s00395-004-0498-4.

12. $\mathrm{Yu} X \mathrm{XJ}$, Li YJ, Xiong Y. Increase of an endogenous inhibitor of nitric oxide synthesis in serum of high cholesterol fed rabbits. Life Sci 1994; 54: 753-758, doi: 10.1016/00243205(94)00443-9.

13. Boger RH, Bode-Boger SM, Sydow K, Heistad DD, Lentz $\mathrm{SR}$. Plasma concentration of asymmetric dimethylarginine, an endogenous inhibitor of nitric oxide synthase, is elevated in monkeys with hyperhomocyst(e)inemia or hypercholesterolemia. Arterioscler Thromb Vasc Biol 2000; 20: 15571564, doi: 10.1161/01.ATV.20.6.1557.

14. Boger RH, Bode-Boger SM, Szuba A, Tsao PS, Chan JR, Tangphao $\mathrm{O}$, et al. Asymmetric dimethylarginine (ADMA): a novel risk factor for endothelial dysfunction: its role in hypercholesterolemia. Circulation 1998; 98: 1842-1847, doi: 10.1161/01.CIR.98.18.1842.

15. Paiva H, Laakso J, Lehtimaki T, Isomustajarvi M, Ruokonen I, Laaksonen R. Effect of high-dose statin treatment on plasma concentrations of endogenous nitric oxide synthase inhibitors. J Cardiovasc Pharmacol 2003; 41: 219-222, doi: 10.1097/00005344-200302000-00010.

16. Vegh A, Szekeres L, Parratt J. Preconditioning of the ischaemic myocardium; involvement of the L-arginine nitric oxide pathway. Br J Pharmacol 1992; 107: 648-652, doi: 10.1111/j.1476-5381.1992.tb14501.x.

17. Penna C, Cappello S, Mancardi D, Raimondo S, Rastaldo $R$, Gattullo D, et al. Postconditioning reduces infarct size in the isolated rat heart: role of coronary flow and pressure and the nitric oxide/cGMP pathway. Basic Res Cardiol 2006; 101: 168-179, doi: 10.1007/s00395-005-0543-6.

18. Weyrich AS, Ma XL, Lefer AM. The role of L-arginine in ameliorating reperfusion injury after myocardial ischemia in the cat. Circulation 1992; 86: 279-288, doi: 10.1161/ 01.CIR.86.1.279.

19. Matos SL, de Paula H, Pedrosa ML, Santos RC, Oliveira EL, Chianca DA Jr, et al. Dietary models for inducing hypercholesterolemia in rats. Braz Arch Biol Technol 2005; 48: 203-209, doi: 10.1590/S1516-89132005000200006.

20. Minicucci MF, Azevedo PS, Duarte DR, Matsubara BB, Matsubara LS, Campana AO, et al. Comparison of different methods to measure experimental chronic infarction size in the rat model. Arq Bras Cardiol 2007; 89: 83-88, doi: 10.1590/S0066-782X2007001400004.

21. Kocsis GF, Pipis J, Fekete V, Kovacs-Simon A, Odendaal L, Molnar E, et al. Lovastatin interferes with the infarct sizelimiting effect of ischemic preconditioning and postconditioning in rat hearts. Am J Physiol Heart Circ Physiol 2008; 294: H2406-H2409, doi: 10.1152/ajpheart.00862.2007. 
22. Kaljusto ML, Mori T, Mohammad Husain RS, Galagudza M, Frantzen ML, Valen G, et al. Postconditioning in rats and mice. Scand Cardiovasc J 2006; 40: 334-341, doi: 10.1080/ 14017430601007587.

23. Dow J, Kloner RA. Postconditioning does not reduce myocardial infarct size in an in vivo regional ischemia rodent model. J Cardiovasc Pharmacol Ther 2007; 12: 153163, doi: 10.1177/1074248407300897.

24. Lefer AM, Weyrich AS, Buerke M. Role of selectins, a new family of adhesion molecules, in ischaemia-reperfusion injury. Cardiovasc Res 1994; 28: 289-294, doi: 10.1093/ $\mathrm{cvr} / 28.3 .289$.

25. Girod WG, Jones SP, Sieber N, Aw TY, Lefer DJ. Effects of hypercholesterolemia on myocardial ischemia-reperfusion injury in LDL receptor-deficient mice. Arterioscler Thromb Vasc Biol 1999; 19: 2776-2781, doi: 10.1161/01.ATV.19.11.2776.

26. Szilvassy Z, Ferdinandy P, Szilvassy J, Nagy I, Karcsu S, Lonovics $J$, et al. The loss of pacing-induced preconditioning in atherosclerotic rabbits: role of hypercholesterolaemia. J Mol Cell Cardiol 1995; 27: 2559-2569, doi: 10.1006/ jmcc.1995.0043.

27. Hoshida S, Yamashita N, Otsu K, Kuzuya T, Hori M. Cholesterol feeding exacerbates myocardial injury in Zucker diabetic fatty rats. Am J Physiol Heart Circ Physiol 2000; 278: $\mathrm{H} 256-\mathrm{H} 262$.

28. Martin C, Schulz R, Post $H$, Boengler $K$, Kelm M, Kleinbongard $P$, et al. Microdialysis-based analysis of interstitial NO in situ: NO synthase-independent NO formation during myocardial ischemia. Cardiovasc Res 2007; 74: 46-55, doi: 10.1016/j.cardiores.2006.12.020.

29. Lu TM, Ding YA, Leu HB, Yin WH, Sheu WH, Chu KM. Effect of rosuvastatin on plasma levels of asymmetric dimethylarginine in patients with hypercholesterolemia. Am J Cardiol 2004; 94: 157-161, doi: 10.1016/j.amjcard.2004.03.052

30. Smirnova IV, Sawamura T, Goligorsky MS. Upregulation of lectin-like oxidized low-density lipoprotein receptor-1 (LOX1) in endothelial cells by nitric oxide deficiency. Am J Physiol Renal Physiol 2004; 287: F25-F32, doi: 10.1152/ajprenal.00449.2003. 